\title{
Elma Üretimi Yapan Bir Tarım İşletmesinde Değer Akış Maliyetleme Yöntemine Göre Örnek Uygulama
} (Araştırma Makalesi)

Example of Application According to the Value Stream Costing Method in an Agribusiness Producing Apple

Doi: 10.29023/alanyaakademik.807959

\section{Ulukan BÜYÜKARIKAN}

Dr. Ö̆ $\breve{g}$ Üyesi, Afyon Kocatepe Üniversitesi, Bolvadin Uygulamall Bilimler Yüksekokulu, Bankacılık ve Sigortacılık Bölümü

ulukan@aku.edu.tr

Orcid No: 0000-0002-1539-7157

Bu makaleye attfta bulunmak için: Büyükarıkan, U. (2021). Elma Üretimi Yapan Bir Tarım İsletmesinde Değer Akış Maliyetleme Yöntemine Göre Örnek Uygulama. Alanya Akademik Bakış, 5(1), 177-191.

\begin{tabular}{|c|c|}
\hline & ÖZET \\
\hline Anahtar kelimeler: & $\begin{array}{l}\text { Issletmelerin detaylı maliyet ve kârlılık analizi yapmaya, israf edilen } \\
\text { kaynakları tespit etmeye olanak sunan değer akıs maliyetleme, yalın üretimi }\end{array}$ \\
\hline Yalın düşünce, & destekleyen önemli bir araçtır. Klasik maliyet muhasebesi; endüstri \\
\hline Yalın muhasebe, & işletmelerinde yetersiz kalmakla birlikte, üretim maliyetlerine ve kaliteye \\
\hline Değer akış & yönelik olumlu bir etkide bulunamamaktadır. Bu sistemi uygulayarak değer \\
\hline maliyetleme, & yaratmayan ve zorunlu olmayan işlemlerin üretim sürecindeki ve maliyetteki \\
\hline $\begin{array}{l}\text { Tarim işletmesi, } \\
\text { Elma üretimi }\end{array}$ & $\begin{array}{l}\text { etkileri yok edilebilmektedir. Özellikle tarımsal üretimde önemli bir yere } \\
\text { sahip olan işgücü, makine ve girdi kullanımının azaltılmasl, tarım }\end{array}$ \\
\hline & $\begin{array}{l}\text { işletmesindeki verimliliği artırmakla kalmayıp, süreçlerin yalınlaşarak } \\
\text { üretim ișlemlerinde uzmanlașmayı ve kaliteyi de beraberinde }\end{array}$ \\
\hline $\begin{array}{l}\text { Makale Gell } \\
\text { 08.10.2020 }\end{array}$ & getirebilecektir. Bu bağlamda çalışmada elma üretimi yapan bir tarım \\
\hline Kabul 1 & işletmesindeki israf tipleri ve değer yaratmayan etkenleri ortadan \\
\hline 10.12 . & $\begin{array}{l}\text { kaldırılarak üretimde kalite ve belirli bir çizgiyi yakalayabilmenin kolay bir } \\
\text { yolu olan değer akış maliyetleme ile ilgili örnek bir uygulama verilmiştir. }\end{array}$ \\
\hline
\end{tabular}

Keywords:

Lean Thinking,

Lean accounting, Value stream costing, Agribusiness, Apple production

\section{ABSTRACT}

Value stream costing, which allows businesses to make detailed cost and profitability analysis and identify wasted resources, is an important tool that supports lean production. Classical cost accounting; although it is insufficient in industrial enterprises, it cannot have a positive effect on production costs and quality. By applying this system, the effects of processes that do not create value and that are not mandatory on the production process and cost can be eliminated. Reducing the use of the workforce, machinery, and inputs, which have an important place especially in agricultural production, will not only increase productivity in the agribusiness but will also bring specialization and quality in production processes by simplifying processes. In this context, the types of waste in an agricultural business that produces apples are given and an example application is given about value flow costing, which is an easy way to catch 


\section{GİRIŞ}

Muhasebe, günümüzün dinamik iş dünyasında, sadece finansal bilgileri toplayan, harmanlayan, analiz eden, yorumlayan ve ileten bir süreç anlamına gelmemektedir. Aynı zamanda karar vericilerin iş dünyasını bir mercek altında görmelerini kolaylaştırmaktadır. $\mathrm{Bu}$ yönüyle muhasebe, iş dünyasının her alanında kullanılabilen ve son derece ölçeklenebilir olan mekanize bir süreçtir. Dolayısıyla bu süreç beklenmedik gelişmelerle başa çıkacak kadar da güçlüdür (Arora ve Soral, 2017: 54). İşletmelerin hayatta kalmaları için rekabet güçlerinde ve müşteri taleplerinde artış sağlamaları gerekmektedir. Bu bağlamda işletmeler ürün fiyatlarını daha cazip bir hale getirebilmek için maliyet azaltmayı kalıcı bir hedef olarak benimsemişlerdir. Nitekim bir süre öncesine kadar işletmelerde üretim yönetimi ve sürekli iyileştirme felsefeleri uygulanmıştır. Günümüzde ise bunun tümleşik uygulamalarla birlikte kullanılması bu yöntemlerin faydalarını daha da artırmıştır. Bununla birlikte üretim işletmelerinde ortaya çıkan zorluklar ve bunları iyileştirme etkenleri aşağıdaki gibidir (Ramos, 2010: 1):

-Müşteri ihtiyaçlarına odaklanmak,

-Mevcut kapasiteyi kullanmak,

-Üretim ve süreç verimsizliklerinin azaltılmak,

-Verimliliği artırmak ve işletme maliyetlerini yönetmek.

Üretim işletmelerinin rekabet güçlerini artırabilmeleri için üretim süreçlerinde sürekli mükemmellik arayışı içerisinde olmaları gerekmektedir. Bu nedenle, üretim sürecinde etkili olan faaliyetleri planlama, bu faaliyetleri kontrol ve değerlendirme, hemen hemen tüm üretim işletmelerinde yaygın olarak kullanılan bir süreçtir. Bu süreç hem üretim sürecinde ortaya çıkabilen birkaç atık türünü ortadan kaldırabilmekte hem de müşteriye değer yaratmayı en üst seviyeye çıkarabilmektedir. İşletmelerdeki süreç iyileştirmelerinin faaliyetler üzerinde meydana getirdiği değişimler, geleneksel performans değerlendirme yaklaşımlarında da değişiklik yapılmasını gerektirmektedir. Böylece işletmeler yeni üretim ortamına uyum sağlayabilmektedirler (Malta ve Cunha, 2011: 234). Bunu gerçekleştirebilmek için üretimde bazı yöntemler uygulanabilmektedir.

$\mathrm{Bu}$ yöntemlerden biri olan yalın düşünce (Lean Thinking), yaratılan mal ve/veya hizmetin üretiminde kaynak tüketimini azaltmaya yönelik bir faaliyettir. Yalın düşünce, üretim etkenlerini daha az kullanarak müşterilerin talep ve beklentilerini karşılamayı hedeflemektedir. Yöntemin temeli, üretim sürecinde değer yaratmayan faaliyetlerin yok edilerek değer yaratan faaliyetlere odaklanmaya ve üretim sürecinin daha hızlı, verimli ve düşük maliyetle gerçekleşmesine dayanmaktadır. Üretim işletmelerinde yalın düşüncenin uygulanabilirliği bu yönteme bir araç olarak hizmet eden değer akış maliyetleme (Value Stream Costing) ile bir arada kullanılmasına bağlıdır (Deran ve Beller, 2014: 162). Değer akış maliyetleme, bir değer akışı eşlemesi ile başlamaktadır. Değer akışı eşleme işlemi, malzeme akışı ve kaynak tahsisi hakkında değer akış maliyetlemede kullanılabilecek gerekli bilgileri üretmektedir. Malzeme akışı, herhangi bir ürünün hangi değer akışından aktığını tanımlamaktadır. Bu aşamada kullanılan değer akışı haritalama işleminde ise işgücünün, 162 
ekipmanın ve boşluğun her değer akışı tarafından nasıl kullanılacağını belirlemektedir. Böylece elde edilen bilgilerden yola çıkarak gerçek değer akışı maliyetleri hesaplanabilir (Maskell ve Katko, 2012).

Değer akışı maliyetlemenin kullanıldığı yalın üretim (Lean Production - LP), en düşük kaynakla en yüksek verimliliğin ortaya çıkmasını, kısaca kaynak israfının önüne geçilerek üretimde ve üründe kaliteyi yakalamayı hedeflemektedir (Serdaroğlu Okur, 1997: 19-20). Üretim sürecindeki sürekli geliştirme ve bunun sonucu olarak ortaya çıkan iyileştirmelerin gerçekleşmesi, değer yaratmayan işlemleri ve bundan dolayı ortadan kalkan malzeme, işçilik ve üretim giderlerini tüketiciye olumlu olarak yansıtmaktadır. Nitekim yalın üretim, ürünün maliyetini önemli ölçüde azaltırken kalitesini de artırmaktadır. Bu sistemi uygulayabilmedeki en önemli etken yalın düşüncenin benimsendiği bir işletmenin varlığı ve yalın muhasebe sistemidir (Kaldırım ve Kaldırım, 2018: 521). Burada değer akış maliyetlemenin gerçekleştirilebilmesi için etkin bir muhasebe bilgi sistemi gerekmektedir. Bu sistem, klasik maliyetleme sistemine ait verilerin işlenerek değer akış aşamalarına göre detaylı biçimde sınıflandırarak; stok değerleme ve satın alma kararlarında, üretim girdilerinin finansmanında, üretim sürecindeki kârlılık ve rantabilite çözümlemesi gibi hayati bilgilere ulaşmada önemli kolaylıklar sağlamaktadır (Karcıoğlu ve Nuray, 2010: 80). Yalın üretimle tümleşik bir değer akışı haritası, yalın üretim kavramlarını örneklendirmek suretiyle, değer akışının uygulanabilirliği artırmak için bilgi ve malzeme akışı oluşturmaktadır (Abuthakeer vd., 2010: 51). Yalın üretim genellikle verimliliği sağlamak ve üretim süreçlerinde belirli bir çizgi oluşturmak amacıyla kullanılmaktadır. Üst yönetim, bu çizginin başarılı olmasını sağlayan koşulların oluşturulmasında kilit bir role sahiptir. Bu koşulların oluşturulmasındaki çabanın \%80'i üst yönetimin uygulama ve davranışlarına aittir (Ramly, 2011). Bu bağlamda yalın üretimin işletmeler tarafindan benimsenmesi, geleneksel muhasebe sistemindeki iyileştirme ihtiyacını motive ederek, işletmeler tarafından israfın ortadan kaldırılmasını sağlamaktadır (Medeiros vd., 2017).

Nitekim yalın üretimin temeli değer yaratmayan ve israfa yol açan faaliyetleri ortadan kaldırarak düşük maliyetli üretim gerçekleştirmeye dayanmaktadır. Tüm üretim işletmelerinde olduğu gibi tarım işletmelerinde de verimliliğin artırılması ve kaynak israfının önlenmesi bir gerekliliktir. Bu bağlamda tarım işletmelerinde yalın üretim uygulanarak kaynak israfının önlenmesi, verimliliğin ve ürün kalitesinin artırılabilmesi sağlanabilir. $\mathrm{Bu}$ kapsamda insanlar açısından hayati önemi bulunan tarım endüstrisine ait bir tarım işletmesi çalışma kapsamında ele alınmıştır. Çalışmada yalın düşünceye sahip bir tarım işletmesinde yalın üretim ve değer akış maliyetleme uygulamasına yer verilerek diğer işletmelere yol göstermek hedeflenmiştir.

\section{LITERATÜR İNCELEMESI}

Dünya çapında üretim, organizasyon ve yönetim sınırlarını aşan bütünsel yaklaşımın temeli uzun yıllar önce atılmıştır (Jasti ve Kodali, 2015). Her şey lider olan Toyota Üretim Sisteminin (Toyata Production System - TPS) tanıtımıyla başlamıştır. Toyota Motor Company'den Taiichi Ohno (Ohno, 1988), TPS üretim sistemindeki her türlü atığı ve tutarsızlığı gidermeyi hedeflemiştir. TPS, Tam Zamanında (Just in Time - JIT) ve Jidoka olmak üzere iki sütundan oluşmaktadır (Ohno, 1988; Liker, 2004). Başlangıçta, çok az araştırmacı (Pettersen, 2009; Monden, 2011) envanter ve somut faydaları azaltma yelpazesi nedeniyle sadece JIT üzerinde yoğunlaşmıştır. JIT'in en iyi özelliği, gerekli ürünü, doğru zamanda, doğru miktarda üretmeyi amaçlaması ve gereksiz stokları ortadan kaldırmasıdır 
(Tiwari vd., 2011). TPS sadece katma değer yaratmayan faaliyetlerin süreçten kaldırılmasını değil, aynı zamanda Jidoka'nın yardımıyla ürünün kalitesini de arttırmaktadır. TPS'nin başarısı, küresel olarak imalat sanayi tarafından geniş kabul görmesiyle sonuçlanmış ve daha sonra diğer geleneksel olmayan endüstrilere yayılmıştır. TPS felsefesi sadece daha geniş çapta tanınan yalın üretim teriminin temelini ortaya atmıştır. LP kavramı, Krafcik (1988) tarafından 'Yalın üretim sisteminin zaferi' makalesiyle ortaya çıkmıştır. Bu kavram, 1990 yılında Womack ve Jones (1996) tarafından Dünyayı Değiştiren Makine adlı kitap ile popüler olmuştur. LP atıkların giderilmesini ele almakta, sürecin daha akıcı ve verimli hale getirilmesini sağlamaktadır (Liker, 1997). Bu, Yalın işletme (Lean Enterprise - LE) kavramını doğurmuştur (Womack ve Jones, 1994). Maskell (2004)'e göre yalın muhasebe: yalın üretimi ve yalın düşünceyi destekleyen; bir işletmenin muhasebe, kontrol, ölçüm ve yönetim süreçlerinde yapılması gereken değişiklikler için kullanılan genel bir terimdir. Maskell (2000) tarafindan yapılan bir sunumda "Yalın muhasebe" kavramı ilk kez ortaya atılmıştır. Resmi bir tanım ortaya konulmadan Maskell yalın üretim uygulayan ve sürdüren işletmelere yalın muhasebenin yararlı olduğu hakkında bilgiler sunmayı amaçlamıştır. Değer akış maliyetleme kavramı yalın muhasebe ve faaliyet maliyeti analizi içeren maliyet yönetimini ifade etmektedir. Womack ve Jones'a (1996) göre bu kavram maliyetleri departmanlara göre sınıflandırmak yerine değer akışlarına göre sınıflandırılmasını önermektedir. Baggaley ve Maskell (2003a) üretimde yalınlığa doğru bir olgunlaşma yolu ortaya koymuştur. Maskell ve Baggaley (2003b) standart maliyetlemenin eksikliklerinden uzaklaşılabilmesi için değer akışlarına dayalı bir organizasyon önermişlerdir. Aksoylu (2014) günümüz bilişim teknolojilerinin yardımıyla geleneksel muhasebe sistemindeki iyileştirmelerin yanında yalın düşünce ve değer akış maliyetleme uygulamalarının kullanılabilmesi mümkün olduğunu ifade etmiştir.

Shah ve Ward (2003)'a göre yalın üretim, tam zamanında ve kalite dâhil olmak üzere çeşitli yönetim uygulamalarını kapsayan çok boyutlu bir yaklaşımdır. Bu yaklaşım, çalışma ekipleri, hücresel üretim, tedarikçi yönetimi vb. unsurları bünyesinde barındırmaktadır. Yalın üretimin temel itici gücü, bu uygulamaların, çok az atıkla veya hiç israf olmadan müşteri talebi hızında bitmiş ürünler üreten, modern, yüksek kaliteli bir sistem oluşturmak için birliktelikle çalışabilmesidir. Arora ve Soral (2017), yalın düşünce insanlara yatırımı motive ederek, ilgili ve eyleme geçirilebilir bilgiler sağlayarak ve organizasyonun her seviyesinde sürekli iyileştirmeyi güçlendirerek desteklemektedir. Maskell ve Baggaley (2006), yalın muhasebenin Genel Kabul Görmüş Muhasebe İlkelerine, dış raporlama düzenlemelerine ve iç raporlama gerekliliklerine tam olarak uyduğunu ifade etmişlerdir.

White vd., (1999)'a göre yalın uygulamalar ve uygulamayı etkileyebilecek faktörler hakkındaki yayın sayısı oldukça azdır. Yalın tekniklerin israfı ortadan kaldırabileceğine dair, inşaat (Howell ve Ballard 1998), havacılık (Hines vd., 2004), hizmet (Bortolotti ve Romano, 2012; Suárez-Barraza vd., 2012), turizm (Vlachos ve Bogdanovic, 2013), hastane (Reijula ve Tommelein, 2012; Young ve McClean 2008), kamu yönetimi (Radnor ve Walley 2008), çay endüstrisi (Vlachos, 2015) örnekleri bulunmaktadır. Yalın düşüncenin evrensel bir tanımının olmamasına rağmen (Shah ve Ward, 2003), yalın düşüncenin benimsenmesinin işletmenin çalışma düzeninde iki yönlü etkisi bulunmaktadır: (a) stratejik düzeyde tanımlamak, yalın düşünme işletmenin değeri (b) faaliyetsel düzeyde tanımlamak, yalın düşünce, atığı ortadan kaldırmak için bir dizi araç ve teknik sağlamaktadır (Hasle vd., 2012). 


\section{YALIN ÜRETIM VE MUHASEBE SISTEMI}

Yalın muhasebe, yalın üretimi aktif olarak uygulayan ve sürdüren üretim tesislerindeki insanlara, faydalı bilgiler sağlamayı amaçlamaktadır. Buna ek olarak yöneticilerin üretim süreçlerini ve iyileştirmelerini anlamasına ve izlemesine olanak tanıyan yerel performans ölçümlerinin geliştirilmesini de içermektedir. Yalın muhasebenin bir başka yönü olan değer akışı maliyetleme yöntemi, basitleştirilmiş bir faaliyet maliyeti analizi biçiminde odaklanmış maliyet bilgilerinin sağlanmasıdır (Maskell, 2004: 46).

Yalın muhasebe, tüm muhasebe ve finans süreçlerine ve sistemlerine yalın düşüncenin uygulanmasıdır. Dolayısıyla herhangi bir kuruluş için başarılı bir yalın dönüşümün önemli bir bileşenidir. $\mathrm{Bu}$ sistemin temelini üç ilke oluşturmakta olup, yalın muhasebeye rehberlik ederek tüm muhasebe çalışanlarının ve kuruluşların etkileşimini sağlamaktadır. Bunlar (BMA, 2020):

Müşteri değeri; ilgili ve güvenilir bilgileri, organizasyon içindeki bilgilerin ilgili tüm kullanıcılara zamanında teslim etmek,

Sürekli iyileştirme; muhasebe süreçlerini, işlevler arası iş süreçlerini ve iş içinde analiz ve karar verme için kullanılan bilgileri iyileştirmek,

Insanlara saygl; işle ilgili sorunların ve bunların temel nedenlerinin işlevler arası, iş birliğine dayalı olacak bir şekilde anlamaya çalışarak bir öğrenme tutumu benimsemektir.

Geleneksel muhasebe ve ölçüm yöntemleri, yalın muhasebenin tam tersidir. Geleneksel muhasebe; iş gücü verimliliği, makine kullanımı ve diğerleri gibi geleneksel ölçümleri, büyük partileri, uzun teslimat sürelerini, yüksek envanteri, kıtlıkları hızlandırmayı ve kriz yönetimini motive etme gibi çeşitli özellikleri bünyesinde barındırmaktadır. Yalın muhasebe ise yalın üretimi (yalın satışları, yalın ürün geliştirme, lider mühendislik, yalın sağlık hizmetleri, vb.) desteklemek için tasarlanmıştır (Maskell, 2016). Diğer bir ifadeyle yalın muhasebe, değer akışında sürekli iyileştirme ve kontrolü desteklemeyi amaçlayan finansal ve işlevsel önlemlerle ilgili çeşitli araçlardan oluşan, yalın düşünce ilkeleri üzerine inşa edilmiş bir işletme yönetim sistemi olarak da tanımlanabilmektedir. Bu yönüyle sistem, muhasebeyi daha verimli hale getirmek için yalın tekniklerin kullanımını ve yalın üretimin avantajlarını yakalayan ve yalın davranışı yönlendiren bir muhasebe sürecini birleştirmektedir. Bir değer akışı, bir ürünün / hizmetin tasarlandığı, üretildiği ve dağıtıldığı süreçte değer akış yelpazesine dayanan bir tekniktir. Malzemelerin, işçiliğin ve her kaynağın maliyetini, değer akışına dayalı yalın üretim sistemlerinde; kolay, anlaşılır, zamanında, verimli, doğrudan değer akışı içinde yakalamayı hedefleyen ve finansal olmayan performans ölçüleriyle birlikte sürekli iyileştirmeler gerçekleştirerek karar alma sürecini destekleyen bir sistemdir (Ruiz-deArbulo-Lopez vd., 2013: 664). Yalın muhasebe, tüm organizasyona yalın düşünceyi yansitmaktadır. Bunlar (Maskell, 2016):

1. Değer akışlarına göre çalışma; finansal ve faaliyetsel raporlamaların tüm değer akışına odaklanması suretiyle tek tek departmanların değil, süreçlerin veya ürünlerin verimliliğine ilişkin bir bütün olarak değer akışının üretkenliğiyle ilgilenmekte ve satış sürecinden başlayarak nakliyeye kadar uzanan bir süreci ifade etmektedir. 
2. Zamanında, sade mali raporlar; finansal ve faaliyetsel raporlama, bir değer akışı düzeyinde olup, genellikle haftalık olarak sunulmaktadır. Benzer şekilde, hayati önem taşıyan faaliyetsel ölçümlerin değer akışları performans panosunda haftalık olarak yayımlanmaktadır.

3. Müşteri değeri; değer akışı ekip üyeleri, müşteriler için yaratılan değere net bir şekilde odaklanmakta ve onların gerçekten neye değer verdiğini tespit ederek onların gözündeki değeri artırırken aynı zamanda maliyeti düşürmeye çalışmaktadır. Dolayısıyla müşteriler için artan değer, müşteri sadakatine, benzeri görülmemiş bir büyümeye ve kârlılığa yol açabilecektir.

4. Karar verme ve kutu skoru; yalın muhasebe, faaliyetsel ve finansal sonuçları belirleyen bir değer akışının üç özelliğini gösteren tek sayfalık bir rapor olan bir "kutu puanı" kullanmaktadır. Bunlar, faaliyetsel performans ölçümleri, kapasite kullanımı ve gelir tablosunun bir özetidir. Kutu puanı, yalın işletmeler için birincil karar verme yöntemidir. Kararlar verildiğinde, kararın bir bütün olarak değer akışı üzerindeki gerçek etkisini anlamak için bilgiler kutu puanına girilir. Kutu puanı, kararın faaliyetsel önlemleri, insan kaynaklarının kullanımını ve değer akışı karlılığını nasıl etkilediğini göstermektedir.

5. Yalın muhasebe daha az iştir; yalın muhasebe departman raporlaması, iş takibi ve diğer sözde kontrol sistemleri gibi geleneksel işletmelerin sorunlarını gidermek için bulunmaktadır.

Yalın Muhasebe İlkeleri, Uygulamaları ve Araçları beş ilke halinde Tablo 1'de gösterilmektedir.

Tablo 1. Yalın Muhasebe İlkeleri, Uygulamaları ve Araçları

\begin{tabular}{|c|c|c|}
\hline İLKELER & UYGULAMALAR & YALIN MUHASEBE ARAÇLARI \\
\hline $\begin{array}{l}\text { A. Yalın } \\
\text { işletme } \\
\text { muhasebesi }\end{array}$ & $\begin{array}{l}\text { 1. İşlem süreçlerinden, raporlardan } \\
\text { ve diğer muhasebe } \\
\text { yöntemlerinden kaynaklanan israfi } \\
\text { sürekli olarak ortadan kaldırma } \\
\end{array}$ & $\begin{array}{l}\text { a. Değer akışı haritalama; mevcut ve } \\
\text { gelecekteki duruma yönelik } \\
\text { b. Kaizen (yalın sürekli iyileştirme) } \\
\text { c. Planla Kontrol Et Yasası problemi çözme } \\
\end{array}$ \\
\hline \multirow[t]{3}{*}{$\begin{array}{l}\text { B. Yalın } \\
\text { dönüşümü } \\
\text { destekleyen } \\
\text { muhasebe } \\
\text { süreçleri }\end{array}$} & $\begin{array}{l}\text { 1. Yönetim kontrolünü ve sürekli } \\
\text { iyileştirme }\end{array}$ & $\begin{array}{l}\text { a. Performans Ölçümü Bağlantı Şeması; Hücre / } \\
\text { süreç, değer akışları, fabrika ve kurumsal } \\
\text { raporlamayı iş stratejisine, hedef maliyetlere ve } \\
\text { yalın iyileştirmeye ilişkin ölçümleri bağlama } \\
\text { b. Aşağıdakileri içeren değer akışı performans } \\
\text { panoları, çığır açan sürekli iyileştirme projeleri } \\
\text { c. Değer akışı performansını gösteren kutu } \\
\text { puanları }\end{array}$ \\
\hline & 2. Maliyet yönetimi & $\begin{array}{l}\text { a. Değer akışı maliyetleme } \\
\text { b. Değer akışı gelir tabloları }\end{array}$ \\
\hline & $\begin{array}{l}\text { 3. Müssteri ve tedarikçi değeri ve } \\
\text { maliyet yönetimi }\end{array}$ & Hedef maliyetleme \\
\hline \multirow{3}{*}{$\begin{array}{l}\text { C. Bilginin } \\
\text { açik ve } \\
\text { zamanında } \\
\text { iletişimi }\end{array}$} & 1. Finansal raporlama & $\begin{array}{l}\text { a. Finansal tablolar } \\
\text { b. Basit, büyük ölçüde nakit esaslı muhasebe }\end{array}$ \\
\hline & $\begin{array}{llr}\text { 2. Finansal ve finansal olmayan } \\
\text { performans ölçümlerinin görsel } \\
\text { raporlaması }\end{array}$ & $\begin{array}{l}\text { Görsel performans panoları kullanarak birincil } \\
\text { raporlama; bölünme, tesis, değer akış1, üretimde } \\
\text { hücre / süreç, ürün tasarımı }\end{array}$ \\
\hline & 3. Karar verme & $\begin{array}{l}\text { Ek maliyet ve kârlılık analizi kullanarak değer } \\
\text { akış maliyeti ve kutu puanları }\end{array}$ \\
\hline D. Yalın bir & 1. Planlama ve bütçe oluşturma & a. Politika dağıtım \\
\hline
\end{tabular}




\begin{tabular}{|c|c|c|}
\hline \multirow{4}{*}{$\begin{array}{l}\text { bakış açısıyla } \\
\text { planlama }\end{array}$} & & b. Satışlar, operasyonlar ve finansal planlama \\
\hline & 2. Yalın iyileştirmenin etkisi & $\begin{array}{l}\text { a. Değer akış maliyeti ve kapasite analizi } \\
\text { b. Mevcut durum ve gelecekteki duruma ilişkin } \\
\text { değer akış haritaları } \\
\text { c. Yalın iyileştirmeden kaynaklanan faaliyetsel, } \\
\text { finansal ve kapasite değişikliklerini gösteren } \\
\text { kutu puanları. Yalın değişikliklerden finansal } \\
\text { fayda planlama }\end{array}$ \\
\hline & 3. Sermaye planlamas 1 & $\begin{array}{l}\text { a. Sermaye harcamalarının artan etkisinin değer } \\
\text { akışı kutu skoru. Genellikle planlama, hazırlama } \\
\text { ve sunma yaklaşımlarıyla kullanılır. }\end{array}$ \\
\hline & 4. İnsanlara yatırım yapma & $\begin{array}{l}\text { a. Sürekli iyileştirme katılımını, çalışanların } \\
\text { memnuniyetini ve çapraz eğitimini takip eden } \\
\text { performans ölçümleri } \\
\text { b. Kâr paylaşımı }\end{array}$ \\
\hline \multirow{2}{*}{$\begin{array}{l}\text { E. } \\
\text { Muhasebede iç } \\
\text { kontrolü } \\
\text { güçlendirme }\end{array}$} & $\begin{array}{l}\text { 1. Yalın faaliyet kontrollerine } \\
\text { dayalı iç kontrol }\end{array}$ & $\begin{array}{l}\text { a. İşlem eleme matrisi } \\
\text { b. Kontrolleri ve denetim risklerini gösteren } \\
\text { süreç haritaları }\end{array}$ \\
\hline & 2. Envanter değerleme & $\begin{array}{l}\text { Sürekli olarak envanter kayıtlarına ve ürün } \\
\text { maliyetlerine gerek kalmadan envanteri } \\
\text { değerlendirmek için kullanılan basit yöntemler } \\
\text { (envanter düşük ve görsel olarak kontrol altında } \\
\text { olduğunda kullanılabilir). }\end{array}$ \\
\hline
\end{tabular}

Kaynak: (Maskell ve Baggaley, 2006: 37)

\subsection{Yalın ve Geleneksel Muhasebe Sistemlerinin Karşılaştırılması}

Geleneksel muhasebe sistemi seri üretimi desteklemek amacıyla ortaya çıkmıştır. Bunun aksine yalın muhasebe sistemi ürünlerin bireysel üretimiyle ilgilenen üretimle ilgili değer akışlarına odaklanan bir sistemdir. Yalın ve geleneksel muhasebe yaklaşımları arasındaki temel fark budur. Dolayısıyla yalın üretim seri üretimi göz ardı etmekte ve kitle üretimine yönelik gereksiz rapor oluşturma ihtiyacının ortadan kaldırılmasını amaçlamaktadır. Her iki sistem arasındaki farklılıklar Tablo 2'de gösterilmektedir.

Tablo 2. Yalın Muhasebe İlkeleri, Uygulamaları ve Araçları

\begin{tabular}{|l|l|l|}
\hline & \multicolumn{1}{|c|}{ Yalın Muhasebe } & \multicolumn{1}{|c|}{ Geleneksel Maliyet Muhasebesi } \\
\hline 1 & $\begin{array}{l}\text { Yalın muhasebe hızlı, basit ve } \\
\text { zamanında yapılır. Karar verme için } \\
\text { doğru bilgi sağlar. }\end{array}$ & $\begin{array}{l}\text { Geleneksel muhasebe sistemleri büyük, karmaşık ve } \\
\text { israflı süreçler olup, büyük oranda değer katmayan } \\
\text { çalışmaları içermektedir. }\end{array}$ \\
\hline 2 & $\begin{array}{l}\text { Finansal tablolar açı ve anlaşılırdır. } \\
\text { Karmaşık finansal muhasebe sistemi nedeniyle } \\
\text { insanların anlaması zordur. }\end{array}$ \\
\hline 3 & $\begin{array}{l}\text { Karar verme için değer akışı } \\
\text { ölçümlerini ve kutu puanını destekler. }\end{array}$ & $\begin{array}{l}\text { Karar vermek için, yalın çabalardan uzak standart } \\
\text { finansal raporlar kullanılmaktadır. }\end{array}$ \\
\hline 4 & $\begin{array}{l}\text { Ürün maliyetlemesi için, bir ürünün tüm } \\
\text { süreciyle ilişkilendirilen bir değer akışı } \\
\text { yaklaşımını destekler. }\end{array}$ & Departman bazında üretim görüşün destekler. \\
\hline 5 & $\begin{array}{l}\text { Değer akışının mali kontrolünü ve } \\
\text { iyileştirilmesini sağlar. }\end{array}$ & Finansal kontrol ve iyileştirmenin odağını daraltır. \\
\hline 6 & $\begin{array}{l}\text { Değer bazlı fiyatlandırma sağlar. } \\
\text { Haftalık değer akışı gelir tablosunu } \\
\text { destekler. Daha sık gelir tabloları daha } \\
\text { iyi bir anlayış ve kontrol sağlar. }\end{array}$ & Yaliliket esaslı fiyatlandırma sağlar. \\
\hline
\end{tabular}




\begin{tabular}{|c|c|c|}
\hline 8 & $\begin{array}{l}\text { örsel yönetim ile daha fazla kontrol } \\
\text { nar. }\end{array}$ & $\begin{array}{l}\text { Herkes tarafindan anlaşılamayan muhasebe mesleki } \\
\text { diliyle çok sayfalı raporlar oluşturur. }\end{array}$ \\
\hline 9 & $\begin{array}{l}\text { alı muhasebe, zamanında ve eksiksiz } \\
\text { ması nedeniyle etkili kontroller } \\
\text { ğlar. }\end{array}$ & $\begin{array}{l}\text { Geleneksel maliyet muhasebesi, aylık döngü, tarihsel } \\
\text { yönelim ve dar odaklanma nedeniyle daha zayıf } \\
\text { kontrollere sahiptir. }\end{array}$ \\
\hline 10 & $\begin{array}{l}\text { esap verebilirlik ve sorumluluğu değer } \\
\text { ış yöneticisine odaklar. }\end{array}$ & Sistemde tüm süreç için hesap verebilirlik eksiktir. \\
\hline 11 & $\begin{array}{l}\text { Finansal bilgiler, kapasite ve faaliyetsel } \\
\text { bilgileri gösteren kutu skorları ile } \\
\text { kolayca entegre olabilen hizlı raporlar } \\
\text { üretir. }\end{array}$ & $\begin{array}{l}\text { Bu sistemde raporlar ancak kayıt tablosu ve standart } \\
\text { maliyetler oluşturulduktan sonra hızlanır ve kolaylaşır. } \\
\text { Raporlar genellikle çok sayıda muhasebe işlemine } \\
\text { dayanır. }\end{array}$ \\
\hline 12 & $\begin{array}{l}\text { ğer akış1 verimini en üst düzeye } \\
\text { armaya dayanır. }\end{array}$ & Birevsel ürün malivetini an aza indirmeve davanur \\
\hline 13 & yunca akışı iyileştirmeye & Standart maliyetlere ve farklılıklara odaklanır. \\
\hline 14 & $\begin{array}{l}\text { jik hedeflerle bağlantılı } \\
\text { motive ederek stratejik } \\
\text { önelmektedir. }\end{array}$ & $\begin{array}{l}\text { liliğini ve makine kullanımını en üst } \\
\text { ayı amaçlar. }\end{array}$ \\
\hline 15 & $\begin{array}{l}\mathrm{Bu} \text { sistemde, işletmeler tümleşik bir } \\
\text { faaliyetsel önlemler, finansal sonuçlar, } \\
\text { kapasite ve akış bilgileri sistemlerine } \\
\text { güvenirler. }\end{array}$ & $\begin{array}{l}\text { ansal bir odağı ya da } \\
\text { lir. }\end{array}$ \\
\hline 16 & $\begin{array}{l}\text { Tek parça akışı, düşük envanteri ve } \\
\text { zamanında teslimatı motive eder. } \\
\text { Akış için tasarlanmıştır. }\end{array}$ & $\begin{array}{l}\text { zun teslimat } \\
\text { arlanmiştır. }\end{array}$ \\
\hline 17 & $\begin{array}{llr}\begin{array}{l}\text { Zamanında } \\
\text { görüntülenen } \\
\text { bulunmaktadır. }\end{array} & \begin{array}{c}\text { görsel } \\
\text { birkaç }\end{array} & \text { olarak } \\
\text { ölçümü }\end{array}$ & $\begin{array}{l}\text { en ve üst düzey } \\
\text { porlara sahiptir }\end{array}$ \\
\hline 18 & $\begin{array}{l}\text { Süreci kontrol etmek ve } \text { süreç } \\
\text { sorunlarını açıkça tanımlamak için } \\
\text { tasarlanmış yerel ölçümleri } \\
\text { bulunmaktadır. }\end{array}$ & $\begin{array}{l}\text { Raporlar insanları ölçmek ve kontrol etmek için } \\
\text { tasarlanmıştır. }\end{array}$ \\
\hline 19 & $\begin{array}{l}\text { Ölçümler, değer akışı ekip üyeleri } \\
\text { tarafından toplanır. Yalın iyileştirmeleri } \\
\text { ve stratejik başarıyı motive ederler. }\end{array}$ & $\begin{array}{llll}\begin{array}{l}\text { Ölçümler ERP } \\
\text { sisteminden } \\
\text { endişelendirebilmektedir. }\end{array} & \begin{array}{l}\text { (Kurumsal } \\
\text { gelir }\end{array} & \begin{array}{l}\text { Kaynak } \\
\text { ve }\end{array} & \begin{array}{l}\text { Planlama) } \\
\text { çalışanlar1 }\end{array} \\
\end{array}$ \\
\hline 20 & $\begin{array}{l}\text { Faaliyetler muhasebe departmanı } \\
\text { tarafindan desteklenmektedir. }\end{array}$ & Komut ve kontrol yönetimini destekler. \\
\hline
\end{tabular}

Kaynak: (Arora ve Soral, 2017: 60-61)

\subsection{Değer Akış Maliyetleme}

Geleneksel muhasebe sistemlerindeki yerleşik ölçümler işletmelerin yalın dönüşüm uygulamalarında sıkıntılar oluşturabilmektedir. İş gücü verimliliği (standart saatlere kıyasla kazanılan saatler), makine kullanımı ve genel gider emilimi gibi ölçümler, muhasebecilerin daha fazla envanter oluşturmalarına neden olmaktadır. Bu durum aşırı üretim ve envanter israfına yol açmaktadır. Geleneksel sistemler seri üretim ve ölçümlerle işletme karlılığı en üst düzeye çıkarabilme varsayımına dayanmakta ve bu durum yalın yaklaşıma oldukça ters düşmektedir. Çünkü yalın üretimi seçen işletmeler açısından da muhasebe, kontrol ve ölçüm yöntemleri önemli ölçüde değişmektedir. Yalın üretim stratejisini yansıtan işletmeler, yalın eylemleri motive eden ve basit ve görsel olarak gösterilebilen performans ölçümleri geliştirmektedir. Değer akışları içindeki üretim hücreleri ve temel süreçler için yapılan 
ölçümler, süreçlerin mükemmel bir ölçüde kontrolünü sağlamaktadır. Bir bütün olarak değer akışına yönelik ölçümler, değer akışı ekibinin sürekli iyileştirme çabalarını yönlendirmektedir. Tesis ve kurumsal ölçümler, üst düzey yöneticilerin işletme stratejilerinin başarısının (veya başarısızlığını) izlenmesini sağlamaktadır. Geleneksel muhasebe sistemleri, ürün maliyetlerinin hesaplanmasına odaklanmaktadır. Bunu gerçekleştirirken genellikle standart veya faaliyet tabanlı maliyetlendirme yöntemleri uygulanılmaktadır. Ürün maliyetleri, daha sonra; karar verme, envanter değerlemesi, fiyatlandırma ve kâr analizi gibi performans ölçümleri için kullanılmaktadır. Ürün maliyetleri her ne kadarda dikkatlice hesaplanmış olsa da genellikle yalın işletmeler için kullanışlı değildir. Yalın işletmeler, işletmenin faaliyetleri boyunca benzer yollar izleyen ürün ailelerinden (veya hizmet ailelerinden) oluşan değer akışlarını oluşturmaktadır. Yalın üretimi benimseyen işletmeler, değer akışları içindeki bireysel ürünler ve bir bütün olarak değer akışlarının maliyetleri hakkında daha fazla ilgililerdir. Ürün maliyetlerinin hesaplanması için karmaşık sistemlere ve gerçek olanı karşılaştırmak amacıyla uzun zaman alan verileri toplamak yerine; standartlara sahip maliyetler ve farklılıkları raporlayan yalın işletmeler, doğrudan değer akış maliyet bilgilerini toplamakta ve sunmaktadır. Geleneksel maliyetleme yöntemlerine yerleşmiş çok sayıda hatalı varsayım bulunmaktadır. Bunlardan ilki "kapasite kullanımı" ve "kapasite fazlası" varsayımıdır. Yalın felsefe ise sürekli olarak yeni kapasite yaratmakta ve bu potansiyeli büyüme stratejisiyle kullanmaktır. Diğer hatalı varsayım da maliyetin ana faktörü ve genel gider tahsisinin itici gücü olarak, emek veya makine zamanının kullanılmasıdır. Yalın bir değerden geçen bir ürünün maliyeti, emek süresine veya makine zamanı bağlı değildir. Bunun yerine değer akışları içindeki ürünlerin maliyetleri konusuna değil bir bütün olarak değer akışlarının maliyetleriyle ilgilenmektedir (Maskell ve Kennedy, 2007: 60-61).

\section{ELMA ÜRETIMI YAPAN TARIM İŞLETMESINDE YALIN YAKLAŞIM}

Ilıman iklim meyve türleri içerisinde küresel üretimi ve tüketimi popüler olan elma, Tanrı Dağlarından (Tian Shan), İpek Yoluna ve Anadolu'ya, Anadolu'dan da Avrupa ve Amerika gibi kıtalara yayılan, kutsal kitaplarda kendine yer edinmiş, önemli bir tarım ürünüdür. Küresel elma üretiminde söz sahibi olan Türkiye, gerek iç tüketime gerekse dış pazara yönelik elma çeşitlerine sahiptir. Elma üretimi yapan orta ölçekli bir tarım işletmesindeki üretim, dış pazara hitap ediyorsa bu işletmede lojistik etmenlerden olan soğuk hava deposu, paketleme ve elleçleme tesisi gibi elemanlar bulunmaktadır. Bu tipteki bir işletmenin kuruluş yeri seçimi üretim yerine zorunlu olarak yakın olsa da gıda ürünleri arzının düşük olması ve ürünlerin belirli şartlarda piyasanın talep ettiği şekilde, yerde ve zamanda bulundurulmasının gerekliliğinden dolayı süreç yalın düşünceye oldukça yatkındır. Bu bağlamda üretim işlemlerinde değer yaratmayan etkenlerin ortadan kaldırılarak üretimde kalite ve belirli bir çizgiyi yakalayabilmenin yolu, değer akış maliyetleme uygulamasıdır. Çünkü klasik maliyet muhasebesi bu tip işletmelerde yetersiz kalmakla birlikte, üretim maliyetlerine ve kaliteye yönelik olumlu bir etkide bulunamamaktadır. Bu sistemi uygulayarak değer yaratmayan ve zorunlu olmayan işlemlerin üretim süreci ve maliyetteki etkileri yok edilebilir. Özellikle üretimde önemli bir yere sahip olan işgücü, makine ve girdi kullanımının azaltılması tarım işletmesindeki verimliliği artırmakla kalmayıp, süreçlerin yalınlaşarak üretim işlemlerinde uzmanlaşmayı ve kaliteyi de beraberinde getirebilecektir.

Elma üretimi yapan bir tarım işletmesinde yalın üretim sistemin aksine israf durumu da meydana gelebilmektedir. İsrafın kaynağı üretimde kullanılan makine, alet ve ekipman, madde, malzeme, insan kaynağı olabilmektedir. 
Tarım işletmesindeki israf tipleri; aşırı uygulama, stoklar, nakliye, hareket, bekleme, hatalar, gereksiz işlem, gereksiz insan kullanımı olup, bunlara ait tanımlamalar ve örnekler Tablo 3'de verilmiştir.

Tablo 3. Tarım işletmesindeki israf tipleri

\begin{tabular}{|c|c|c|}
\hline İsraf tipleri & Tanım & Örnek \\
\hline Aşırı uygulama & $\begin{array}{l}\text { Tarımsal üretimi } \text { gerçekleştirmek } \\
\text { için yapılan uygulamaların } \\
\text { gereğinden fazla yapılması }\end{array}$ & $\begin{array}{l}\text { Toprak işleme, bitki koruma, gübreleme } \\
\text { ve sulamamanın gereğinden fazla } \\
\text { yapılması }\end{array}$ \\
\hline Stoklar & $\begin{array}{l}\text { Gereğinden fazla madde ve malzeme } \\
\text { bulundurulmasi sonucu tarim } \\
\text { işletmesinde finansman, nakliye, } \\
\text { depolama, bozulma gibi oluşan } \\
\text { giderler }\end{array}$ & $\begin{array}{l}\text { Tarımsal üretim fazlalığının } \\
\text { depolanamamasından kaynaklanan } \\
\text { çürüme, tarım ilaçlarında, tarımsal } \\
\text { gübrelerde bozulma vb. }\end{array}$ \\
\hline Nakliye & $\begin{array}{l}\text { Tarımsal üretimin yapıldığ } \text { alanla } \\
\text { tamamlayıc hizmetler arasındaki } \\
\text { mesafe nedeniyle sürece katkıda } \\
\text { bulunmayan giderler. }\end{array}$ & $\begin{array}{l}\text { Soğuk hava deposu, paketleme ve } \\
\text { elleçleme tesisi gibi pazarlama } \\
\text { elemanlarının tarımsal üretim alanına } \\
\text { uzak olması nedeniyle ortaya çıkan } \\
\text { giderler. }\end{array}$ \\
\hline Hareket & $\begin{array}{l}\text { Çalışanların, alet ya da makinaların } \\
\text { üretime ya da hizmete katkıda } \\
\text { bulunmayacak } \\
\text { çalıştırılması. }\end{array}$ & $\begin{array}{l}\text { Üretimde kullanılan traktörün gereksiz } \\
\text { yere kullanılması. }\end{array}$ \\
\hline Bekleme & $\begin{array}{l}\text { İşlemleri gerçekleştirmek için ya da } \\
\text { bir sonraki işlemi beklerken boşa } \\
\text { geçen zaman }\end{array}$ & $\begin{array}{l}\text { Hasat döneminde soğuk hava deposuna } \\
\text { yükleme-boşalma işlemi yaparken } \\
\text { meydana gelen bekleme }\end{array}$ \\
\hline Hatalar & $\begin{array}{l}\text { İşleri yanlış yaparak, hataların tespit } \\
\text { edilmesi ile bunların düzeltilmesi } \\
\text { için harcanan zaman ve paradır. }\end{array}$ & $\begin{array}{l}\text { İlaçlama zamanında gecikme sonucunda } \\
\text { hastalık ve zararlıları bitkiye ve/veya } \\
\text { tarım ürününe vermiş olduğu zararı } \\
\text { azaltabilmek için yapılan bitki koruma } \\
\text { uygulamaları. }\end{array}$ \\
\hline Gereksiz işlem & $\begin{array}{l}\text { Üretime ya da hizmete hiçbir değer } \\
\text { katmayan işlemler. }\end{array}$ & $\begin{array}{l}\text { Gereğinden fazla sulama. } \\
\text { Gereğinden fazla bitki koruma } \\
\text { uygulamaları. } \\
\text { Gereğinden fazla toprak işleme. }\end{array}$ \\
\hline $\begin{array}{l}\text { Gereksiz } \\
\text { kullanımı }\end{array}$ & $\begin{array}{l}\text { İnsan kaynağının gereksiz biçimde } \\
\text { kullanımı. }\end{array}$ & $\begin{array}{l}\text { Hasat döneminde gereğinden fazla işçi } \\
\text { çalıştırılması. }\end{array}$ \\
\hline
\end{tabular}

Kaynak: (Deran ve Beller, 2014: 168)'den uyarlanmıştır.

\subsection{Elma Üretimi Yapan Tarım İşletmesinde Değer Akış Maliyetleme Uygulanması}

Elma üretimi yapan bir tarım işletmesinden alınan bilgilerden yola çıkılarak ve üretim biriminde değer akışları incelenerek değer akış birimleri örnek olayda ortaya konulmuştur.

Tarım işletmelerinde değer akış maliyetleri gerek işgücü gerekse madde ve malzeme maliyetleri belirlenirken, direkt/endirekt ayrımı yapılmamakta olup, tüm maliyet unsurları dikkate alınmaktadır. Bunlar; işgücü, malzeme, makine-araç-gereç, destek, dış işlem, tesis ${ }^{1}$ ve diğer giderlerden oluşmaktadır (Baggaley ve Maskell, 2003b: 5).

1 Tesis giderleri (yatırım dönemi) elma üretimi için oluşturulan elma bahçesinin tesis döneminden (işletmede kullanılan elma anacına göre 2 yıl) üretim döneminin başlangıcına kadar yapılan giderlerin toplamının elma 170 
Tarım işletmesinin geleneksel gelir tablosundaki giderler Tablo 4'te verilmiştir.

Tablo 4. Tarım işletmesinin geleneksel gelir tablosu

\begin{tabular}{|l|r|}
\hline & Toplam \\
\hline Net Satışlar & 1.500 .000 \\
\hline Satılan Malın Maliyeti & $(1.100 .000)$ \\
\hline Bürüt Satış Kârı & 400.000 \\
\hline Faaliyet Giderleri & $(100.000)$ \\
\hline Faaliyet Kârı & 300.000 \\
\hline
\end{tabular}

Tarım işletmesindeki malzeme giderleri; toprak işleme, sulama sistemi ve su, gübre, bitki koruma ilaçları, hasat ve diğer kullanılan malzeme giderleridir. İşçilik giderleri ise; toprak işleme, budama, sulama, bitki koruma, hasat ve diğer işçilik giderlerinden oluşmaktadır. Tarım işletmesinde değer akış maliyetleme temelinde oluşturulan örnek gelir tablosu formatı Tablo 5'de gösterilmektedir.

Tablo 5. Tarım işletmesindeki değer akıș gelir tablosu

\begin{tabular}{|l|r|r|r|r|}
\hline & Değer akışı & Değer akışı & Destekleme giderleri & \multicolumn{1}{c|}{ Toplam } \\
\hline Net satışlar & 1.500 .000 & - & - & 1.500 .000 \\
\hline Toplam Maliyetler & $(1.100 .000)$ & - & - & 1.100 .000 \\
\hline Malzeme Giderleri & 450.000 & - & - & 450.000 \\
\hline İşücü Giderleri & 300.000 & - & - & 300.000 \\
\hline Alet-Makine-ekipman giderleri & 250.000 & - & - & 250.000 \\
\hline Diğer Giderler & 100.000 & - & - & 100.000 \\
\hline $\begin{array}{l}\text { Stok Değişimi Öncesi Değer Akış } \\
\text { Kârı }\end{array}$ & 400.000 & - & - & 400.000 \\
\hline $\begin{array}{l}\text { Stoklardaki Azalış } \\
\text { (Azalış Ya Da Artış) }\end{array}$ & $(50.000)$ & - & - & \multirow{2}{*}{$(50.000)$} \\
\hline Değer Akış Kârı & & & - & 350.000 \\
\hline Taşıma Maliyetleri & 350.000 & - & - & 50.000 \\
\hline Net Faaliyet Kârı & $(50.000)$ & - & - & 300.000 \\
\hline Satış Kârı (Return on sales) & 300.000 & - & - & 0,20 \\
\hline
\end{tabular}

Kaynak: Maskell ve Kennedy, 2007: 64)'ten uyarlanmıştır.

Tarım işletmesi, değer akışlarına göre ele alınarak oluşturulan değer akış gelir tablosunda bulunan kâr tutarlarında herhangi bir farklılık bulunmadığı belirlenmiştir. Buna karşın değer akış gelir tablosunda yer alan gider kalemlerinin ayrıntılı bir biçimde yer edinmesi giderlerin nedenlerini belirginleştirmekle birlikte, faaliyetler ve değer akışları bazında çözümleme yapilabilmesine olanak sunmaktadır.

\section{SONUÇ}

Endüstri işletmelerinin rekabet gücünü artırmaları için üretim süreçlerinde, kalite ve maliyette daha iyiyi gerçekleştirme arayışına yönelmeleri gerekmektedir. $\mathrm{Bu}$ bağlamda günümüz işletmeleri açısından rekabet gücü, müşteri taleplerini karşılama ve ürün fiyatları gibi unsurlar işletme stratejileri açısından oldukça önemlidir. Seri üretim anlayışının günümüzdeki önemi giderek azaldığından dolayı, üretimde yalınlaşma felsefesine dayalı uygulamalar kendine yer edinmeye başlamıştır.

bahçesinin ekonomik ömrüne bölünmesiyle elde edilerek bahçenin üretim dönemlerine yansıtılan giderleri ifade etmektedir. 
Üretim işletmelerinde, kaynak tüketimini azaltmaya yönelik olan yöntemlerden biri olan yalın düşünce üretim etkenlerini daha az kullanarak müşterilerin talep ve beklentilerini karşılamayı hedeflemektedir. Bu yöntemin temeli değer yaratmayan ve israfa yol açan faaliyetleri ortadan kaldırarak düşük maliyetli üretim gerçekleştirmeye dayanmaktadır.

Uygulama açısından yalın üretimin aracı olan değer akış maliyetleme (value stream costing) işletmenin faaliyetlerindeki etkinliğinde, kontrolünde ve planlamada mükemmelliği yakalamaya hizmet etmektedir. Değer akış maliyetleme, geleneksel maliyet muhasebesinin gerçekleştiremediği detaylı maliyet ve kârlılık analizi yapmaya, israf edilen kaynakları tespit etmeye imkân tanımaktadır. Bununla birlikte geleneksel muhasebeye nazaran finansal tabloların açık ve anlaşılır olması; değer akışının finansal kontrolünü ve iyileştirilmesini sağlayarak doğru bilgilerin hızlı, basit ve zamanında karar verme için kullanılmasını kolaylaştırmaktadır. Ayrıca değer bazlı fiyatlandırma, haftalık değer akışı gelir tablosu ve görsel yönetimle birlikte verimlilikteki artışın yanı sıra hesap verilebilirlik ve şeffaflık açısından işletmeye katkıda bulunmaktadır. Sistem bu yönüyle stratejik hedeflerle bağlantılı bir biçimde stratejik başarıya doğru yönelmektedir.

Çalışmada elma üretimi yapan orta ölçekli bir tarım işletmesinde işletmenin kuruluş yeri seçimi üretim yerine zorunlu olarak yakın olsa da gıda ürünleri arzının düşük olması ve ürünlerin belirli şartlarda piyasanın talep ettiği şekilde, yerde ve zamanda bulundurulmasının gerekliliğinden dolayı işletme faaliyetleri açısından yalın düşünceye oldukça yatkındır. Elma üretimi yapan bir tarım işletmesinde yalın üretim sistemin aksine israf durumu da meydana gelebilmektedir. İsrafin kaynağı üretimde kullanılan makine, alet ve ekipman, madde, malzeme, insan kaynağı olabilmektedir. Bu bağlamda çalışmada tarım işletmesindeki israf tipleri verilmiş ve değer yaratmayan etkenleri ortadan kaldırılarak üretimde kalite ve belirli bir çizgiyi yakalayabilmenin kolay bir yolu olan değer akış maliyetleme uygulanmıştır.

Klasik maliyet muhasebesi bu tip işletmelerde yetersiz kalmakla birlikte, üretim maliyetlerine ve kaliteye yönelik olumlu bir etkide bulunamamaktadır. Bu sistemin uygulanmasıyla değer yaratmayan ve zorunlu olmayan işlemlerin üretim süreci ve maliyetteki etkileri yok edilebileceği ifade edilebilir. Özellikle üretimde önemli bir yere sahip olan işgücü, makine ve girdi kullanımının azaltılması, tarım işletmesindeki verimliliği artırmakla kalmayıp, süreçlerin yalınlaşarak üretim işlemlerinde uzmanlaşmayı ve kaliteyi de beraberinde getirebilecektir.

\section{KAYNAKÇA}

ABUTHAKEER, S. S., MOHANRAM, P. V. ve KUMAR, G. M. (2010). "Activity based costing value stream mapping". International Journal of Lean Thinking, 1(2): 51-64.

AKSOYLU, S. (2014). "Hastane işletmelerinde değer akış maliyetlemesi". Niğde Üniversitesi İ̈BF Dergisi, 7(1): 260-272.

ARORA, V. ve SORAL, G. (2017). "Conceptual issues in lean accounting: A review". IUP Journal of Accounting Research \& Audit Practices, 16(3): 54-63.

BAGGALEY, B. L. ve MASKELL, B. L. (2003a). "Value stream management for lean companies, part I". Journal of Cost Management, 17(2): 23-27.

BAGGALEY, B. L. ve MASKELL, B. L. (2003b). "Value stream management for lean companies, part II". Journal of Cost Management, 17(3): 24-30. 
BMA (BMA Company), (2020). "Overview of Lean Accounting”, https://maskell.com/overview/, 02.10.2020.

BORTOLOTTI, T. ve ROMANO, P. (2012). "Lean first, then automate: a framework for process improvement in pure service companies. A case study". Production Planning \& Control, 23(7): 513-522.

DERAN, A. ve BELLER, B. (2014). "Hastanelerde yalın yönetimin bir aracı olarak değer akış maliyetleme ve kamu hastanesinde bir uygulama”. Selçuk Üniversitesi Sosyal Bilimler Enstitüsü Dergisi, (32): 161-174.

HASLE, P., BOJESEN, A., LANGAA JENSEN, P. ve BRAMMING, P. (2012). "Lean and the working environment: a review of the literature". International Journal of Operations \& Production Management, 32(7): 829-849.

HINES, P., HOLWEG, M. ve RICH, N. (2004). "Learning to evolve: A review of contemporary lean thinking". International Journal of Operations \& Production Management, 24(10): 994-1011.

HOWELL, G. ve BALLARD, G. (1998). "Implementing lean construction: understanding and action", In Proc. Sixth Annual Conference of the International Group for Lean Construction. Sao Paulo, Brazil, 13-15 Ağustos 1998.

JASTI, N. V. K., KODALI, R. (2015). "Lean production: literature review and trends". International Journal of Production Research, 53(3): 867-885.

KALDIRIM, Y. ve KALDIRIM, Z. (2018). “Değer Akış Maliyet Yönteminin Yalın Üretim Sistemindeki Yeri ve Önemi Üzerine Bir İnceleme". İşletme Araştırmaları Dergisi, 10(4): 520-535.

KARCIOĞLU, R. ve NURAY, M. (2010). "Yeni Bir Maliyetleme Sistemi Olarak Değer Akış Maliyetleme". Muhasebe ve Finansman Dergisi, (47): 69-80.

KRAFCIK, J. F. (1988). “Triumph of the lean production system”. MIT Sloan Management Review, 30(1): 41.

LIKER, J. K. (1997). Becoming lean: Inside stories of US manufacturers, CRC Press, Florida.

LIKER, J. K. (2004). The Toyota Way, McGraw-Hill, New York.

MALTA, J. ve CUNHA, P. F. (2011). “A new approach for cost modelling and performance evaluation within operations planning”. CIRP Journal of Manufacturing Science and Technology, 4(3): 234-242.

MASKELL, B. H. (2000). "Lean accounting for lean manufacturers". Manufacturing Engineering, 125(6): 46-53.

MASKELL, B. H. (2004). “What is lean accounting?”. Superfactory Newsletter, 5(5): 46-53.

MASKELL, B. H. (2016). "Why lean accounting?", https://www.ame.org/target/articles/2016/why-lean-accounting, 02.10.2020.

MASKELL, B. H. ve BAGGALEY, B. L. (2006). "Lean accounting: What's it all about?". Target Magazine, 22(1): 35-43. 
MASKELL, B. H. ve BAGGALEY, B. L. (2004). Practical Lean Accounting: A Proven System for Measuring and Managing the Lean Enterprise, Productivity Press, New York.

MASKELL, B. H. ve KENNEDY, F. A. (2007). "Why do we need lean accounting and how does it work?". Journal of Corporate Accounting \& Finance, 18(3): 59-73.

MASKELL, B. ve KATKO, N. (2012). Value stream costing: The lean solution to standard costing complexity and waste, Stenzel, J. (eds). Lean accounting: Best practices for sustainable integration, New York, John Wiley \& Sons.

MEDEIROS, H. D. S., SANTANA, A. F. B. ve GUIMARÃES, L. D. S. (2017). "O uso dos métodos de custeio nas indústrias de manufatura enxuta: uma análise da literature". Gestão \& Produção, 24(2): 395-406.

MONDEN, Y. (2011). Toyota production system: an integrated approach to just-in-time, CRC Press, Florida.

OHNO, T. (1988). Toyota production system: beyond large-scale production, CRC Press, Florida.

PETTERSEN, J. (2009). "Defining lean production: some conceptual and practical issues". The TQM Journal, 21 (2): 127-142.

RADNOR, Z. ve WALLEY, P. (2008). "Learning to walk before we try to run: adapting lean for the public sector". Public money and management, 28(1): 13-20.

RAMLY, E. F. (2011). "Sustaining and spreading the gains in lean Hospitals: Role of Leadership". International Conference on Continuous Value Adding based on Lean Thinking in Hospital Management, Tehran, Iran, 30 Kasım-1 Aralık 2011.

RAMOS, M. Z. R. G. (2010). Sincronização da cadeia de valor através da integração da teoria das restrições e produção lean, Doktora Tezi, Faculdade de Ciências e Tecnologia.

REIJULA, J. ve TOMMELEIN, I. D. (2012). "Lean hospitals: a new challenge for facility designers". Intelligent Buildings International, 4(2): 126-143.

RUIZ-de-ARBULO-LOPEZ, P., FORTUNY-SANTOS, J. ve CUATRECASAS-ARBÓS, L. (2013). "Lean manufacturing: costing the value stream". Industrial Management \& Data Systems, 113(5): 647-668.

SERDAROĞLU OKUR, A. (1997). Yalın Üretim: 2000'li Yıllara Doğru Türkiye İçin Yapılanma Modeli, Söz Yayınları, İstanbul.

SHAH, R. ve WARD, P. T. (2003). "Lean manufacturing: context, practice bundles, and performance". Journal of operations management, 21(2): 129-149.

SUÁREZ-BARRAZA, M. F., SMITH, T. ve DAHLGAARD-PARK, S. M. (2012). "Lean Service: A literature analysis and classification”. Total Quality Management \& Business Excellence, 23(3-4): 359-380.

TIWARI, S., DUBEY, R. ve TRIPATHI, N. (2011). “The journey of lean”. Indian Journal of Commerce \& Management Studies, 2(2): 200-208. 
VLACHOS, I. (2015). "Applying lean thinking in the food supply chains: a case study". Production Planning \& Control, 26(16): 1351-1367.

VLACHOS, I. ve BOGDANOVIC, A. (2013). "Lean thinking in the European hotel industry". Tourism Management, 36: 354-363.

WHITE, R. E., PEARSON, J. N. ve WILSON, J. R. (1999). "JIT Manufacturing: a survey of implementation in small and large US manufacturers". Management Science 45(1): 115

WOMACK, J. P. ve JONES, D. T. (1994). "From lean production to the lean enterprise". Harvard business review, 72(2): 93-103.

WOMACK, J. P. ve JONES, D. T. (1996). Lean Thinking: Banish Waste and Create Wealth in Your Corporation, Simon \& Schuster, New York.

YOUNG, T. P. ve McCLEAN, S. I. (2008). “A critical look at Lean Thinking in healthcare". BMJ Quality \& Safety, 17(5): 382-386. 